\title{
A spectral relaxation method for thermal dispersion and radiation effects in a nanofluid flow
}

Peri K Kameswaran, Precious Sibanda* and Sandile S Motsa

${ }^{*}$ Correspondence:

sibandap@ukzn.ac.za

School of Mathematical Sciences,

University of KwaZulu-Natal, Private

Bag X01 Scottsville,

Pietermaritzburg, 3209, South Africa

\begin{abstract}
In this study we use a new spectral relaxation method to investigate heat transfer in a nanofluid flow over an unsteady stretching sheet with thermal dispersion and radiation. Three water-based nanofluids containing copper oxide $\mathrm{CuO}$, aluminium oxide $\mathrm{Al}_{2} \mathrm{O}_{3}$ and titanium dioxide $\mathrm{TiO}_{2}$ nanoparticles are considered in this study. The transformed governing system of nonlinear differential equations was solved numerically using the spectral relaxation method that has been proposed for the solution of nonlinear boundary layer equations. Results were obtained for the skin friction coefficient, the local Nusselt number as well as the velocity, temperature and nanoparticle fraction profiles for some values of the governing physical and fluid parameters. Validation of the results was achieved by comparison with limiting cases from previous studies in the literature. We show that the proposed technique is an efficient numerical algorithm with assured convergence that serves as an alternative to common numerical methods for solving nonlinear boundary value problems. We show that the convergence rate of the spectral relaxation method is significantly improved by using the method in conjunction with the successive over-relaxation method.
\end{abstract}

Keywords: spectral relaxation method; heat transfer; stretching sheet; nanofluids

\section{Introduction}

In recent years flow and heat transfer over a stretching surface has been extensively investigated due to its importance in industrial and engineering applications such as in the heat treatment of materials manufactured in extrusion processes and the casting of materials. Controlled cooling of stretching sheets is needed to assure quality products. Fiber technology, wire drawing, the manufacture of plastic and rubber sheets and polymer extrusion are some of the important processes that take place subject to stretching and heat transfer. The quality of the final product depends to a great extent on the heat controlling factors, and the knowledge of radiative heat transfer in the system can perhaps lead to a desired product with a sought characteristic.

The development of a boundary layer over a stretching sheet was first studied by Crane [1], who found an exact solution for the flow field. This problem was then extended by Gupta and Gupta [2] to a permeable surface. The flow problem due to a linearly stretching sheet belongs to a class of exact solutions of the Navier-Stokes equations. Since the pioneering work of Sakiadis [3], various aspects of the stretching problem involving New-

\section{第 Springer}

(c)2013 Kameswaran et al.; licensee Springer. This is an Open Access article distributed under the terms of the Creative Commons Attribution License (http://creativecommons.org/licenses/by/2.0), which permits unrestricted use, distribution, and reproduction in any medium, provided the original work is properly cited. 
tonian and non-Newtonian fluids have been extensively studied by several authors (see Cortell [4], Hayat and Sajid [5], Liao [6], Xu [7]).

The study of radiation effects has important applications in engineering. Thermal radiation effect plays a significant role in controlling heat transfer process in polymer processing industry. Many studies have been reported on flow and heat transfer over a stretched surface in the presence of radiation (see El-Aziz [8, 9], Raptis [10], Mahmoud [11]). El-Aziz [12] studied the radiation effect on the flow and heat transfer over an unsteady stretching sheet. He found that the heat transfer rate increases with increasing radiation and unsteadiness parameters and the Prandtl number. The effect of the radiation parameter on the heat transfer rate was found to be more noticeable at larger values of the unsteadiness parameter and the Prandtl number. In addition to radiation, it is important to consider the thermal dispersion effect on boundary layer flow since this has a direct impact on the heat transfer rate. Several studies on hydrodynamic dispersion have been reported in the literature. The double-dispersion phenomenon in a Darcian, free convection boundary layer adjacent to a vertical wall, using multi-scale analysis arguments, was investigated by Telles and Trevisan [13].

In recent years tremendous effort has been given to the study of nanofluids. The word nanofluid coined by Choi [14] describes a liquid suspension containing ultra fine particles (diameter less than $50 \mathrm{~nm}$ ). Experimental studies (e.g., Masuda et al. [15], Das et al. [16], Xuan and Li [17]) showed that even with a small volumetric fraction of nanoparticles (usually less than $5 \%$ ), the thermal conductivity of the base liquid is enhanced by $10-50 \%$ with a remarkable improvement in the convective heat transfer coefficient. The literature on nanofluids was reviewed by Trisaksri and Wongwises [18], Wang and Mujumdar [19] among several others. Nanofluids thus provide an alternative to many common fluids for advanced thermal applications in micro and nano-heat transfer applications. Thermophysical properties of nanofluids such as thermal conductivity, diffusivity and viscosity were studied by Kang et al. [20], Velagapudi et al. [21], Rudyak et al. [22]. Hady et al. [23] studied the radiation effect on the viscous flow of a nanofluid and heat transfer over a nonlinearly stretching sheet. They observed that the increase in the thermal radiation parameter and the nonlinear stretching sheet parameter yields a decrease in the nanofluid temperature leading to an increase in the heat transfer rate. The boundary layer flow of a nanofluid with radiation was studied by Olanrewaju et al. [24]. They observed that radiation has a significant influence on both the thermal boundary layer thickness and the nanoparticle volume fraction profiles.

Recently, Mahdy [25] studied the effects of unsteady mixed convection boundary layer flow and heat transfer of nanofluids due to a stretching sheet. He found that the heat transfer rate at the surface increased with the mixed convection parameter and the solid volume fraction of nanoparticles. Moreover, the skin friction increased with the mixed convection parameter and decreased with the unsteadiness parameter and the nanoparticle volume fraction. Narayana and Sibanda [26] studied the effects of laminar flow of a nanoliquid film over an unsteady stretching sheet. They found that the unsteadiness parameter has the effect of thickening the momentum boundary layer while thinning the thermal boundary layer for $\mathrm{Cu}$-water and $\mathrm{Al}_{2} \mathrm{O}_{3}$-water nanoliquids. Kameswaran et al. [27] studied the effects of hydromagnetic nanofluid flow due to a stretching or shrinking sheet with viscous dissipation and chemical reaction effects. They observed that the velocity profile de- 
creased with an increase in the nanoparticle volume fraction, while the opposite was true in the case of temperature and concentration profiles.

The objective of this study is to analyze the effects of fluid and physical parameters such as thermal dispersion, nanoparticle volume fraction and radiation parameters on the flow and heat transfer characteristics of three different water based nanofluids containing copper oxide $\mathrm{CuO}$, aluminium oxide $\mathrm{Al}_{2} \mathrm{O}_{3}$ and titanium dioxide $\mathrm{TiO}_{2}$ nanoparticles. The momentum and energy equations are coupled and nonlinear. By using suitable similarity variables, we convert these equations into coupled ordinary differential equations and solve them numerically via a novel iteration scheme called the spectral relaxation method (SRM) (see Motsa and Makukula [28], Mosta [29]). The SRM is an iterative algorithm for the solution of nonlinear boundary layer problems which are characterized by flow properties that decay exponentially to constant levels far from the boundary surface. The key features of the method are the decoupling of the governing nonlinear systems into a sequence of smaller sub-systems which are then discretized using spectral collocation methods. The method is very efficient in solving boundary layer equations of the type under investigation in this study. In cases where the SRM convergence is slow, it is demonstrated that successive over-relaxation can be used to accelerate convergence and improve the accuracy of the method. The current results were validated by comparison with published results in the literature and results obtained using the Matlab bvp $4 \mathrm{c}$ routine. We further show that substantial improvement in the convergence rate of the SRM may be realized by using this method in conjunction with the successive over relaxation method.

\section{Mathematical formulation}

\section{Transient unsteady-state flow and heat transfer $(t>0)$}

This study is concerned with the laminar boundary layer flow of an incompressible nanofluid over a stretching sheet. The origin of the system is located at the slit from which the sheet is drawn, with $x$ and $y$ denoting coordinates along and normal to the sheet. The fluid is a water-based nanofluid containing either alumina, copper-oxide or titanium-oxide nanoparticles. The base fluid and the nanoparticles are in thermal equilibrium and no slip occurs between them. The sheet is stretched with velocity

$$
U_{w}(x, t)=\frac{b x}{1-\alpha t}
$$

along $x$-axis, where $b$ and $\alpha$ are positive constants with dimensions (time) $)^{-1}$ and $\alpha t<1$. The surface temperature distribution

$$
T_{w}(x, t)=T_{\infty}+T_{0}\left[\frac{b x^{r_{1}}}{v_{f}}\right](1-\alpha t)^{-m}
$$

varies both along the sheet and with time where $T_{0}$ is a reference temperature, $T_{\infty}$ is the ambient temperature and $v_{f}$ is the kinematic viscosity of the fluid. Under these assumptions, the boundary layer equations governing the flow, heat and concentration fields can be written in a dimensional form (see Tiwari and Das [30]) as follows:

$$
\frac{\partial u}{\partial x}+\frac{\partial v}{\partial y}=0
$$




$$
\begin{aligned}
& \frac{\partial u}{\partial t}+u \frac{\partial u}{\partial x}+v \frac{\partial u}{\partial y}=\frac{\mu_{n f}}{\rho_{n f}} \frac{\partial^{2} u}{\partial y^{2}}, \\
& \frac{\partial T}{\partial t}+u \frac{\partial T}{\partial x}+v \frac{\partial T}{\partial y}=\alpha_{n f} \frac{\partial^{2} T}{\partial y^{2}}-\frac{1}{\left(\rho C_{p}\right)} \frac{\partial q_{n f}}{\partial y}+\frac{\partial}{\partial y}\left(\alpha_{y} \frac{\partial T}{\partial y}\right) .
\end{aligned}
$$

The initial conditions are:

$$
u(x, 0)=u(x), \quad v(x, 0)=0, \quad T(x, 0)=T_{w}(x) .
$$

The appropriate boundary conditions for equations (1)-(3) have the form:

$$
\begin{aligned}
& u(x, t)=U_{w}(x, t), \quad v(x, t)=0, \quad T(x, t)=T_{w}(x, t) \quad \text { at } y=0, \\
& u(x, t) \rightarrow 0, \quad T(x, t) \rightarrow T_{\infty} \quad \text { as } y \rightarrow \infty
\end{aligned}
$$

where $u, v$ are the velocity components in the $x$ and $y$ directions, respectively, $T$ is the fluid temperature, $C_{p}$ is the specific heat at constant pressure, $r_{1}$ and $m$ are constants, the expression for the effective thermal diffusivity taken as $\alpha_{y}=\alpha_{m}+\gamma d u, \alpha_{m}$ is the molecular thermal diffusivity, $\gamma d u$ represent thermal diffusivity, $\gamma$ is the mechanical thermal dispersion coefficient and $d$ is the pore diameter.

Following Rosseland's approximation, $T^{4}$ is expressed as a linear function of the temperature $T^{4} \equiv 4 T_{\infty}^{3} T-3 T_{\infty}^{4}$ and the radiative heat flux $q_{r}$ is modeled as

$$
\frac{\partial q_{r}}{\partial y}=-\frac{16 \sigma^{*} T_{\infty}^{3}}{3 k^{*}} \frac{\partial^{2} T}{\partial y^{2}}
$$

where $\sigma^{*}$ is the Stefan-Boltzman constant and $k^{*}$ is the mean absorption coefficient. The effective dynamic viscosity of the nanofluid was given by Brinkman as

$$
\mu_{n f}=\frac{\mu_{f}}{(1-\phi)^{2.5}}
$$

where $\phi$ is the solid volume fraction of spherical nanoparticles. The effective density of each nanofluid is given as

$$
\rho_{n f}=(1-\phi) \rho_{f}+\phi \rho_{s}
$$

The thermal diffusivity of the nanofluid is

$$
\alpha_{n f}=\frac{k_{n f}}{\left(\rho C_{p}\right)_{n f}},
$$

where the heat capacitance of the nanofluid is given by

$$
\left(\rho C_{p}\right)_{n f}=(1-\phi)\left(\rho C_{p}\right)_{f}+\phi\left(\rho C_{p}\right)_{s}
$$

The thermal conductivity of the nanofluids is approximated by the Maxwell-Garnett (MG) model (Maxwell-Garnett [31] and Guerin et al. [32]):

$$
k_{n f}=k_{f}\left[\frac{k_{s}+2 k_{f}-2 \phi\left(k_{f}-k_{s}\right)}{k_{s}+2 k_{f}+\phi\left(k_{f}-k_{s}\right)}\right] \text {. }
$$


The subscripts $n f, f$ and $s$ represent the thermophysical properties of the nanofluid, base fluid and nanoparticles, respectively. The continuity equation (1) is satisfied by introducing a stream function $\psi(x, y, t)$, where

$$
u=\frac{\partial \psi}{\partial y} \quad \text { and } \quad v=-\frac{\partial \psi}{\partial x}
$$

with

$$
\psi(x, y, t)=\left(\frac{v_{f} b}{1-\alpha t}\right)^{\frac{1}{2}} x f(\eta) \text { and } \eta=\left[\frac{b}{v_{f}(1-\alpha t)}\right]^{\frac{1}{2}} y,
$$

where $f(\eta)$ is the dimensionless stream function. The velocity components are then given by

$$
u=\left(\frac{b x}{1-\alpha t}\right) f^{\prime}(\eta) \quad \text { and } \quad v=-\left(\frac{v_{f} b}{1-\alpha t}\right)^{\frac{1}{2}} f(\eta) .
$$

The temperature is represented as

$$
T=T_{\infty}+\left(T_{w}-T_{\infty}\right) g(\eta)
$$

where $g(\eta)$ is the dimensionless temperature. On using equations (6)-(15), equations (2), (3) and (5) transform into the following two-point boundary value problem:

$$
\begin{aligned}
& f^{\prime \prime \prime}+\phi_{1}\left[f^{\prime \prime}-f^{\prime 2}-S\left(\frac{\eta}{2} f^{\prime \prime}+f^{\prime}\right)\right]=0, \\
& g^{\prime \prime}\left[1+D f^{\prime}+\frac{k_{R}}{\phi_{2}}\left(\frac{k_{n f}}{k_{f}}\right)\right]+D f^{\prime \prime} g^{\prime}+\operatorname{Pr}\left[f g^{\prime}-r_{1} f^{\prime} g-S\left(\frac{\eta}{2} g^{\prime}+m g\right)\right]=0, \\
& f(0)=0, \quad f^{\prime}(0)=1, \quad f^{\prime}(\infty) \rightarrow 0, \\
& g(0)=1, \quad g(\infty) \rightarrow 0,
\end{aligned}
$$

where

$$
k_{R}=1+\frac{4}{3 N_{R}} .
$$

The non-dimensional constants in equations (16) and (17) are the unsteadiness parameter $S$, the thermal dispersion parameter $D$, the radiation parameter $N_{R}$ and the Prandtl number $P r$. They are respectively defined as

$$
S=\frac{\alpha}{b}, \quad D=\frac{\gamma d U_{w}}{\alpha_{m}}, \quad N_{R}=\frac{k_{n f} k^{*}}{4 \sigma^{*} T_{\infty}^{3}}, \quad \operatorname{Pr}=\frac{\nu_{f}\left(\rho C_{p}\right)_{f}}{k_{f}},
$$

where

$$
\phi_{1}=(1-\phi)^{2.5}\left[1-\phi+\phi\left(\frac{\rho_{s}}{\rho_{f}}\right)\right] \quad \text { and } \quad \phi_{2}=1-\phi+\phi \frac{\left(\rho_{C p}\right)_{s}}{\left(\rho_{C p}\right)_{f}} .
$$

The thermophysical properties of water and nanofluids used in this paper are given in Table 1. 
Table 1 Thermophysical properties of water and nanoparticles, Oztop and Abu-Nada [33]

\begin{tabular}{lccc}
\hline Properties $\rightarrow$ & $\boldsymbol{\rho}\left(\mathbf{k g} / \mathbf{m}^{\mathbf{3}}\right)$ & $\boldsymbol{C}_{\boldsymbol{p}}(\mathbf{J} / \mathbf{k g K})$ & $\boldsymbol{k}(\mathbf{W} / \mathbf{m K})$ \\
\hline Pure water & 997.1 & 4,179 & 0.613 \\
$\mathrm{CuO}$ & 3,620 & 531.8 & 76.5 \\
$\mathrm{Al}_{2} \mathrm{O}_{3}$ & 3,970 & 765 & 40 \\
$\mathrm{TiO}_{2}$ & 4,250 & 686.2 & 8.9538 \\
\hline
\end{tabular}

\section{Skin friction and heat transfer coefficients}

In addition to velocity and temperature, the quantities of engineering interest in heat transport problems are the skin friction coefficient $C_{f}$ and the local Nusselt number $N u_{x}$. These parameters respectively characterize the surface drag and wall heat transfer rate. The shear stress at the wall is given by

$$
\tau_{w}=-\mu_{n f}\left[\frac{\partial u}{\partial y}\right]_{y=0}=-\frac{1}{(1-\phi)^{2.5}} \rho_{f} v_{f}^{\frac{1}{2}}\left(\frac{b}{1-\alpha t}\right)^{\frac{3}{2}} x f^{\prime \prime}(0)
$$

The skin friction coefficient is defined as

$$
C_{f}=\frac{2 \tau_{w}}{\rho_{f} U_{w}^{2}}
$$

and using equation (23) in equation (24), we obtain

$$
C_{f}(1-\phi)^{2.5} \operatorname{Re}_{x}^{\frac{1}{2}}=-2 f^{\prime \prime}(0)
$$

The heat transfer rate at the surface is given by

$$
q_{w}=-k_{n f}\left[\frac{\partial T}{\partial y}\right]_{y=0}=-k_{n f}\left(T_{w}-T_{\infty}\right)\left(\frac{b}{v_{f}(1-\alpha t)}\right)^{\frac{1}{2}} g^{\prime}(0) .
$$

The Nusselt number is defined as

$$
N u_{x}=\frac{x}{k_{f}} \frac{q_{w}}{T_{w}-T_{\infty}}
$$

Using equation (26) in equation (27), we obtain the dimensionless wall heat transfer rate as

$$
\frac{N u_{x}}{\operatorname{Re}_{x}^{\frac{1}{2}}}\left(\frac{k_{f}}{k_{n f}}\right)=-g^{\prime}(0)
$$

where $R e_{x}$ is the local Reynolds number defined by $R e_{x}=x U_{w} / v_{f}$.

\section{Initial steady state flow and heat transfer $(t \leq 0)$}

In the case of steady state solution, i.e., $S \rightarrow 0$, equations (16) and (17) along with boundary conditions (18) and (19) are replaced by

$$
f^{\prime \prime \prime}+\phi_{1}\left[f^{\prime \prime}-f^{\prime 2}\right]=0
$$




$$
\begin{aligned}
& g^{\prime \prime}\left[1+D f^{\prime}+\frac{k_{R}}{\phi_{2}}\left(\frac{k_{n f}}{k_{f}}\right)\right]+D f^{\prime \prime} g^{\prime}+\operatorname{Pr}\left[f g^{\prime}-r_{1} f^{\prime} g\right]=0, \\
& f(0)=0, \quad f^{\prime}(0)=1, \quad f^{\prime}(\infty) \rightarrow 0, \\
& g(0)=1, \quad g(\infty) \rightarrow 0 .
\end{aligned}
$$

The momentum boundary layer equation is partially decoupled from the energy equation. The solution is obtained by looking for an exponential function of the form $f^{\prime}(\eta)=$ $e^{-s \eta}$ that satisfies both the differential equation and governing boundary conditions over the interval $[0, \eta]$, and the exact solution to (29) and (30) is

$$
f(\eta)=\frac{1-e^{-s \eta}}{s}
$$

where $s$ is a parameter associated with the nanoparticle volume fraction. This satisfies the equation

$$
s=\sqrt{\phi_{1}} .
$$

We note that from equation (33) we obtain $f^{\prime \prime}(0)=-s$. In the case of a clear fluid, we have $s=1$ and solution (33) reduces to Crane's solution for a stretching sheet problem given by

$$
f(\eta)=1-e^{-\eta} \quad \text { with } f^{\prime \prime}(0)=-1 .
$$

Here we presented the solution of a heat transfer equation in the absence of thermal dispersion as a particular case. Equation (30) is replaced by

$$
g^{\prime \prime}-\operatorname{Pr}\left(\frac{k_{f}}{k_{n f}}\right) \frac{\phi_{2}}{k_{R}}\left[r_{1} f^{\prime} g-f g^{\prime}\right]=0 .
$$

Introducing a new variable

$$
\xi=-\frac{P r}{s^{2}} e^{-s \eta},
$$

equation (35) and thermal boundary conditions (32) take the form:

$$
\begin{aligned}
& \xi g_{\xi \xi}+\left[1-\lambda_{1}\left(P r^{*}+\xi\right)\right] g_{\xi}+\lambda_{1} r_{1} g=0, \\
& g\left(-P r^{*}\right)=1, \quad g\left(0^{-}\right) \rightarrow 0,
\end{aligned}
$$

where $\lambda_{1}=\left(\frac{k_{f}}{k_{n f}}\right) \frac{\phi_{2}}{k_{R}}$ and $\operatorname{Pr}{ }^{*}=\operatorname{Pr} / s^{2}$ is the modified Prandtl number.

The solution of equation (37) is obtained in terms of confluent hypergeometric functions in the following form:

$$
g(\xi)=C_{0} \xi^{\alpha} M\left[\alpha-r_{1}, \alpha+1, \lambda_{1} \xi\right]
$$

where

$$
M[a, b, z]=\sum_{r=0}^{\infty} \frac{a(a+1) \cdots(a+r-1)}{b(b+1) \cdots(b+r-1)} \frac{z}{r !}
$$


is Kummer's function. Making use of boundary conditions (38) and rewriting the solution in terms of the variable $\eta$, we get

$$
g(\eta)=\frac{e^{-s \eta \alpha} M\left[\alpha-r_{1}, \alpha+1,-\alpha e^{-s \eta}\right]}{M\left[\alpha-r_{1}, \alpha+1,-\alpha\right]} .
$$

The surface heat transfer rate has the exact value

$$
g^{\prime}(0)=\frac{\left(\frac{\alpha-r_{1}}{\alpha+1}\right) M\left[\alpha-r_{1}+1, \alpha+2,-\alpha\right]-S \alpha M\left[\alpha-r_{1}, \alpha+1,-\alpha\right]}{M\left[\alpha-r_{1}, \alpha+1,-\alpha\right]},
$$

where

$$
\alpha=\lambda_{1} \operatorname{Pr}^{*}
$$

\section{The spectral relaxation method}

In this section we give a brief description of the spectral relaxation method (SRM) that is employed to solve equations (16)-(17); see also Motsa and Makukula [28]. The SRM is proposed for the solution of similarity boundary layer problems with exponentially decaying profiles. For self-similar boundary layer problems, the SRM algorithm may be summarized as follows:

1. Reduce the order of the momentum equation for $f(\eta)$ by introducing the transformation $f^{\prime}(\eta)=p(\eta)$ and express the original equation in terms of $p(\eta)$.

2. Assuming that $f(\eta)$ is known from a previous iteration (denoted by $f_{r}$ ), construct an iteration scheme for $p(\eta)$ by assuming that only linear terms in $p(\eta)$ are to be evaluated at the current iteration level (denoted by $p_{r+1}$ ) and all other terms (linear and nonlinear) are assumed to be known from the previous iteration. In addition, nonlinear terms in $p$ are evaluated at the previous iteration.

3. The iteration schemes for the other governing dependent variables are developed in a similar manner but now using the updated solutions of the variables determined in the previous equation.

The strategy described above is analogous to the Gauss-Seidel idea of decoupling linear algebraic system of equations. Using this algorithm leads to a sequence of linear differential equations with variable coefficients which can easily be solved using standard numerical techniques for solving linear differential equations. In this study we discretize the differential equations using Chebyshev spectral collocation methods (see, for example, [34, 35]). Spectral methods are preferred here because of their remarkably high accuracy and ease of implementation in discretizing and the subsequent solution of variable-coefficient linear differential equations with smooth solutions over simple domains. In the context of the SRM iteration scheme described above, equations (16)-(19) become

$$
\begin{aligned}
& p_{r+1}^{\prime \prime}+\phi_{1} f_{r} p_{r+1}^{\prime}-\phi_{1} S\left[p_{r+1}+\frac{\eta}{2} p_{r+1}^{\prime}\right]=\phi_{1} p_{r}^{2}, \\
& f_{r+1}^{\prime}=p_{r+1}, \quad f_{r+1}(0)=0, \\
& g_{r+1}^{\prime \prime}+D g_{r+1}^{\prime \prime} p_{r+1}+\left(\frac{k_{n f}}{k_{f}}\right)\left(1+\frac{4}{3 N_{R}}\right)\left(\frac{1}{\phi_{2}}\right) g_{r+1}^{\prime \prime} \\
& \quad+D p_{r+1}^{\prime} g_{r+1}^{\prime}+\operatorname{Pr}\left[f_{r+1} g_{r+1}^{\prime}-r_{1} p_{r+1} g_{r+1}-S\left(m g_{r+1}+\frac{\eta}{2} g_{r+1}^{\prime}\right)\right]=0,
\end{aligned}
$$


subject to boundary conditions

$$
\begin{array}{ll}
p_{r+1}(0)=1, & p_{r+1}(\infty) \rightarrow 0, \\
g_{r+1}(0)=1, & g_{r+1}(\infty) \rightarrow 0 .
\end{array}
$$

We apply the Chebyshev spectral collocation method to solve the decoupled system (42)-(46). For details of spectral methods, we refer the interested reader to [34, 35]. Before applying the spectral method, it is convenient to transform the domain on which the governing equation is defined to the interval $[-1,1]$ on which the spectral method can be implemented. We use the transformation $\eta=L(\tau+1) / 2$ to map the interval $[0, L]$ to $[-1,1]$, where $L$ is chosen to be large enough to numerically approximate the conditions at infinity. The basic idea behind the spectral collocation method is the introduction of a differentiation matrix $\mathcal{D}$ which is used to approximate the derivatives of the unknown variables at the collocation points as the matrix vector product of the form

$$
\frac{d f_{r}}{d \eta}=\sum_{k=0}^{N} \mathbf{D}_{l k} f_{r}\left(\tau_{k}\right)=\mathbf{D f}_{r}, \quad l=0,1, \ldots, N
$$

where $N+1$ is the number of collocation points (grid points), $\mathbf{D}=2 \mathcal{D} / L$, and $\mathbf{f}=$ $\left[f\left(\tau_{0}\right), f\left(\tau_{1}\right), \ldots, f\left(\tau_{N}\right)\right]^{T}$ is the vector function at the collocation points. Higher-order derivatives are obtained as powers of $\mathbf{D}$, that is,

$$
f_{r}^{(p)}=\mathbf{D}^{p} \mathbf{f}_{r},
$$

where $p$ is the order of the derivative.

Applying the spectral method to equations (42)-(44), we obtain

$$
\begin{array}{lll}
A_{1} \mathbf{p}_{r+1}=B_{1}, & p_{r+1}\left(\tau_{\bar{N}}\right)=1, & p_{r+1}\left(\tau_{0}\right)=0 \\
A_{2} \mathbf{f}_{r+1}=B_{2}, & f_{r+1}\left(\tau_{\bar{N}}\right)=0, & \\
A_{3} \mathbf{g}_{r+1}=B_{3}, & g_{r+1}\left(\tau_{\bar{N}}\right)=1, & g_{r+1}\left(\tau_{0}\right)=0,
\end{array}
$$

where

$$
\begin{aligned}
A_{1}= & \mathbf{D}^{2}+\operatorname{diag}\left[\phi_{1} \mathbf{f}_{r}-\phi_{1} S \frac{\eta}{2}\right] \mathbf{D}-\phi_{1} S \mathbf{I}, \quad B_{1}=\phi_{1} p_{r}^{2} \\
A_{2}= & \mathbf{D}, \quad B_{2}=p_{r+1} \\
A_{3}= & \operatorname{diag}\left[1+D \mathbf{p}_{r+1}+\frac{1}{\phi_{2}}\left(\frac{k_{n f}}{k_{f}}\right)\left(1+\frac{4}{3 N_{R}}\right)\right] \mathbf{D}^{2} \\
& +\operatorname{diag}\left[D \mathbf{p}_{r+1}^{\prime}+\operatorname{Pr}\left(\mathbf{f}_{r+1}-S \frac{\eta}{2}\right)\right] \mathbf{D}-r_{1} \operatorname{Pr} \operatorname{diag}\left[\mathbf{p}_{r+1}\right]-\operatorname{Pr} S m \mathbf{I}, \quad B_{3}=\mathbf{O} .
\end{aligned}
$$

In equations (52)-(54), $\mathbf{I}$ is an identity matrix. The size of the matrix $\mathbf{O}$ is $(N+1) \times 1$ and $\operatorname{diag}[]$ is a diagonal matrix, all of size $(\bar{N}+1) \times(\bar{N}+1)$ where $\bar{N}$ is the number of grid points, $\mathbf{f}, \mathbf{g}$ and $\mathbf{p}$ are the values of the functions $f, g$ and $p$, respectively, when evaluated at the grid points and the subscript $r$ denotes the iteration number. 
The initial guesses to start the SRM scheme for equations (49)-(51) are chosen as functions that satisfy the boundary conditions. From physical considerations, the velocity and temperature profiles for the boundary layer problem discussed in this work decay exponentially at $\eta=\infty$. For this reason, it is convenient to choose the following exponential functions as initial guesses:

$$
f_{0}(\eta)=1-e^{-\eta}, \quad p_{0}(\eta)=e^{-\eta}, \quad g_{0}(\eta)=e^{-\eta}
$$

The convergence rate of the SRM algorithm can be significantly improved by applying the successive over-relaxation (SOR) technique to equations (49)-(51). Under the SOR framework, a convergence controlling relaxation parameter $\omega$ is introduced and the SRM scheme for finding, say $X$, is modified to

$$
A X_{r+1}=(1-\omega) A X_{r}+\omega B
$$

The results in the next section show that for $\omega<1$, applying the SOR method improves the efficiency and accuracy of the SRM.

\section{Results and discussion}

We have studied heat transfer in a nanofluid flow due to an unsteady stretching sheet. We considered three different nanoparticles, copper oxide $(\mathrm{CuO})$, aluminium oxide $\left(\mathrm{Al}_{2} \mathrm{O}_{3}\right)$ and titanium oxide $\left(\mathrm{TiO}_{2}\right)$, with water as the base fluid.

The spectral relaxation method algorithm (49)-(51) has been used to solve the nonlinear coupled boundary value problem due to flow over a steady stretching sheet in a nanofluid. We established the accuracy of the spectral relaxation method by comparing the SRM results with those obtained using the Matlab bvp4c solver. The comparison in Tables 3-8 shows a good agrement between the two methods. This comparison provides a benchmark to measure the accuracy and efficiency of the method.

The heat transfer coefficients are shown in Table 2 for different values of the unsteadiness parameter and the Prandtl number. The smaller Prandtl numbers in Table 2 suggest a greater rate of thermal diffusion compared to momentum diffusion so that heat conduction is more significant than convection, while $\operatorname{Pr}=10$ (for example, water at 1 bar and $280 \mathrm{~K}$ ) is indicative of processes where convection is more effective than conduction. It is clear that the heat transfer coefficient increases with an increase in the Prandtl numbers.

Table 2 Effect of the unsteadiness parameter and a comparison of wall temperature gradient

\begin{tabular}{|c|c|c|c|c|}
\hline \multirow[t]{2}{*}{$\operatorname{Pr}$} & \multirow[t]{2}{*}{$S$} & \multicolumn{3}{|l|}{$-g^{\prime}(0)$} \\
\hline & & El-Aziz [12] & bvp4c & SRM \\
\hline 0.1 & 0.8 & 0.4517 & 0.45148717 & 0.45148717 \\
\hline 1.0 & & 1.6728 & 1.67284531 & 1.6728453 \\
\hline 10 & & 5.70503 & 5.70597574 & 5.7059757 \\
\hline 0.1 & 1.2 & 0.5087 & 0.50850265 & 0.50850265 \\
\hline 1.0 & & 1.818 & 1.81800501 & 1.8180050 \\
\hline 10 & & 6.12067 & 6.12102434 & 6.1210243 \\
\hline 0.1 & 2 & 0.604013 & 0.60351763 & 0.60351763 \\
\hline 1.0 & & 2.07841 & 2.07841323 & 2.07841323 \\
\hline 10 & & 6.88506 & 6.88615127 & 6.88615127 \\
\hline
\end{tabular}
$-g^{\prime}(0)$ for different values of the Prandtl number 
Table 3 Effect of fluid unsteadiness on the skin friction and a comparison of bvp4c with SRM when $\operatorname{Pr}=2, D=1, \phi=0, r_{1}=2, m=1.5, \omega=0.75$ and $N_{R}=1$

\begin{tabular}{lllllll}
\hline $\boldsymbol{S}$ & \multicolumn{2}{l}{ Basic SRM } & & \multicolumn{2}{l}{ SRM with SOR } & bvp4c \\
\cline { 2 - 3 } & Iter & $-\boldsymbol{f f}^{\prime \prime}(\mathbf{0})$ & & Iter & $-\boldsymbol{f}^{\prime \prime}(\mathbf{0})$ & \\
\hline 0.5 & 38 & 1.16721152 & & 14 & 1.16721152 & 1.16721152 \\
1 & 23 & 1.32052206 & 14 & 1.32052206 & 1.32052206 \\
1.5 & 18 & 1.45966589 & 13 & 1.45966589 & 1.45966589 \\
\hline
\end{tabular}

Table 4 Effect of $S, \operatorname{Pr}, D$ and $N_{R}$ on the heat transfer coefficient and a comparison of bvp4c with SRM for fixed values of $\phi=0, r_{1}=2, m=1.5$

\begin{tabular}{|c|c|c|c|c|c|}
\hline \multirow[t]{2}{*}{$S$} & \multirow[t]{2}{*}{$P r$} & \multirow[t]{2}{*}{$D$} & \multirow[t]{2}{*}{$N_{R}$} & \multicolumn{2}{|l|}{$-g^{\prime}(0)$} \\
\hline & & & & bvp4c & SRM \\
\hline $\begin{array}{l}0 \\
0.5 \\
1 \\
1.5\end{array}$ & 7 & 1 & 1 & $\begin{array}{l}1.73404471 \\
1.98512673 \\
2.21161765 \\
2.41898107\end{array}$ & $\begin{array}{l}1.73404471 \\
1.98512673 \\
2.21161765 \\
2.41898107\end{array}$ \\
\hline 1.5 & $\begin{array}{l}3 \\
4 \\
5 \\
6 \\
7\end{array}$ & 1 & 1 & $\begin{array}{l}1.52380810 \\
1.78458969 \\
2.01570707 \\
2.22549552 \\
2.41898107\end{array}$ & $\begin{array}{l}1.52380810 \\
1.78458969 \\
2.01570707 \\
2.22549552 \\
2.41898107\end{array}$ \\
\hline 1.5 & 2 & $\begin{array}{l}0 \\
1 \\
5\end{array}$ & 1 & $\begin{array}{l}1.45831884 \\
1.21745970 \\
0.77377295\end{array}$ & $\begin{array}{l}1.45831884 \\
1.21745970 \\
0.77377295\end{array}$ \\
\hline 1.5 & 2 & 1 & $\begin{array}{r}1 \\
5 \\
10\end{array}$ & $\begin{array}{l}1.21745970 \\
1.40695145 \\
1.43699000\end{array}$ & $\begin{array}{l}1.21745970 \\
1.40695145 \\
1.43699000\end{array}$ \\
\hline
\end{tabular}

Table 2 also gives a comparison between the spectral relaxation method and the established Matlab bvp4c solver. The present results are in good agreement with the earlier findings by El-Aziz [12]. The numerical methods give results that are consistent to nine significant digits after 38 iterations of the spectral relaxation method.

Tables 3-4 show the skin friction and the heat transfer coefficients (which are respectively proportional to $-f^{\prime \prime}(0)$ and $\left.-g^{\prime}(0)\right)$ for different levels of unsteadiness within the problem. Table 3 gives a comparison of the SRM results in the absence of the nanoparticle volume fraction (i.e., $\phi=0$ ). Firstly, we observe that both the skin friction and the heat transfer coefficients increase with unsteadiness. The skin friction increases as the unsteadiness parameter increases. This is a consequence of the inverted boundary layer that is formed. The negative values of $f^{\prime \prime}(0)$ are an indication that the solid surface exerts a drag force on the fluid. This is due to the fact that the development of the boundary layer is caused solely by the stretching sheet. Secondly, we note that the number of iterations required for the two methods to give a consistent solution decreases as the unsteadiness parameter increases. We further note that the number of iterations to convergence of the SRM decreases by more than a factor of 2 if the SRM is used in conjunction with the SOR method. The fact that the SRM solutions are in good agreement with the bvp4c results is indicative of the accuracy and robustness of the spectral relaxation method.

Table 4 shows the effect of flow unsteadiness, the Prandtl number, thermal dispersion and the radiation parameter on the heat transfer coefficient in the absence of nanoparticles. The heat transfer coefficient decreases with an increase in thermal dispersion and increases with thermal radiation. The results show that the rate of unsteady heat transfer 
Table 5 Effect of unsteadiness and the solid volume fraction on the skin friction coefficient and a comparison of bvp4c with SRM for different values of nanoparticle volume fraction with CuO-water nanofluid for fixed values of $\operatorname{Pr}=6.7850, D=1, r_{1}=2, m=1.5, N_{R}=1$ and $\omega=0.75$

\begin{tabular}{|c|c|c|c|c|c|c|}
\hline \multirow[t]{2}{*}{$S$} & \multirow[t]{2}{*}{$\phi$} & \multicolumn{2}{|c|}{ Basic SRM } & \multicolumn{2}{|c|}{ SRM with SOR } & \multirow[t]{2}{*}{ bvp4c } \\
\hline & & Iter & $-f^{\prime \prime}(0)$ & Iter & $-f^{\prime \prime}(0)$ & \\
\hline 0.5 & $\begin{array}{l}0.05 \\
0.1 \\
0.15 \\
0.2\end{array}$ & $\begin{array}{l}38 \\
37 \\
38 \\
35\end{array}$ & $\begin{array}{l}1.16449176 \\
1.14990897 \\
1.12498006 \\
1.09094877\end{array}$ & $\begin{array}{l}14 \\
14 \\
13 \\
13\end{array}$ & $\begin{array}{l}1.16449176 \\
1.14990897 \\
1.12498006 \\
1.09094877\end{array}$ & $\begin{array}{l}1.16449176 \\
1.14990897 \\
1.12498006 \\
1.09094877\end{array}$ \\
\hline 1 & $\begin{array}{l}0.05 \\
0.1 \\
0.15 \\
0.2\end{array}$ & $\begin{array}{l}23 \\
23 \\
23 \\
23\end{array}$ & $\begin{array}{l}1.31744508 \\
1.30094687 \\
1.27274360 \\
1.23424238\end{array}$ & $\begin{array}{l}14 \\
13 \\
14 \\
14\end{array}$ & $\begin{array}{l}1.31744508 \\
1.30094687 \\
1.27274360 \\
1.23424238\end{array}$ & $\begin{array}{l}1.31744508 \\
1.30094687 \\
1.27274360 \\
1.23424238\end{array}$ \\
\hline 1.5 & $\begin{array}{l}0.05 \\
0.1 \\
0.15 \\
0.2\end{array}$ & $\begin{array}{l}18 \\
18 \\
18 \\
18\end{array}$ & $\begin{array}{l}1.45626469 \\
1.43802806 \\
1.40685300 \\
1.36429489\end{array}$ & $\begin{array}{l}13 \\
13 \\
13 \\
14\end{array}$ & $\begin{array}{l}1.45626469 \\
1.43802806 \\
1.40685300 \\
1.36429489\end{array}$ & $\begin{array}{l}1.45626469 \\
1.43802806 \\
1.40685300 \\
1.36429489\end{array}$ \\
\hline
\end{tabular}

Table 6 Comparison of $-g^{\prime}(0)$ obtained by bvp4c and SRM for different values of nanoparticle volume fraction with CuO-water nanofluid for fixed values of $\operatorname{Pr}=6.7850, D=1, r_{1}=2$, $m=1.5, \omega=0.75$ and $N_{R}=1$

\begin{tabular}{|c|c|c|c|c|c|c|}
\hline \multirow[t]{2}{*}{$S$} & \multirow[t]{2}{*}{$\phi$} & \multicolumn{2}{|c|}{ Basic SRM } & \multicolumn{2}{|c|}{ SRM with SOR } & \multirow[t]{2}{*}{ bvp4c } \\
\hline & & Iter & $-g^{\prime}(0)$ & Iter & $-g^{\prime}(0)$ & \\
\hline$\overline{0.5}$ & $\begin{array}{l}0.05 \\
0.1 \\
0.15 \\
0.2\end{array}$ & $\begin{array}{l}38 \\
37 \\
37 \\
35\end{array}$ & $\begin{array}{l}1.85367196 \\
1.75916556 \\
1.66693860 \\
1.57677868\end{array}$ & $\begin{array}{l}14 \\
14 \\
13 \\
13\end{array}$ & $\begin{array}{l}1.85367196 \\
1.75916556 \\
1.66693860 \\
1.57677868\end{array}$ & $\begin{array}{l}1.85367196 \\
1.75916556 \\
1.66693860 \\
1.57677868\end{array}$ \\
\hline 1 & $\begin{array}{l}0.05 \\
0.1 \\
0.15 \\
0.2\end{array}$ & $\begin{array}{l}23 \\
23 \\
23 \\
23\end{array}$ & $\begin{array}{l}2.06861805 \\
1.96536212 \\
1.86412754 \\
1.76472535\end{array}$ & $\begin{array}{l}14 \\
13 \\
14 \\
14\end{array}$ & $\begin{array}{l}2.06861805 \\
1.96536212 \\
1.86412754 \\
1.76472535\end{array}$ & $\begin{array}{l}2.06861805 \\
1.96536212 \\
1.86412754 \\
1.76472535\end{array}$ \\
\hline 1.5 & $\begin{array}{l}0.05 \\
0.1 \\
0.15 \\
0.2\end{array}$ & $\begin{array}{l}18 \\
18 \\
18 \\
18\end{array}$ & $\begin{array}{l}2.26481693 \\
2.15317826 \\
2.04340762 \\
1.93533542\end{array}$ & $\begin{array}{l}13 \\
13 \\
13 \\
14\end{array}$ & $\begin{array}{l}2.26481693 \\
2.15317826 \\
2.04340762 \\
1.93533542\end{array}$ & $\begin{array}{l}2.26481693 \\
2.15317826 \\
2.04340762 \\
1.93533542\end{array}$ \\
\hline
\end{tabular}

can be accelerated by the thermal dispersion. The thermal dispersion may be regarded as the effect of mixing to enhance heat transfer in the medium. Table 4 further gives a comparison of the SRM and the bvp4c results in the case $\phi=0$. The spectral relaxation method converges to the numerical solutions for all parameter values matching the bvp $4 \mathrm{c}$ results up to nine significant digits.

Tables 5 and 6 show the skin friction coefficient and heat transfer rate for various physical parameters in the case of a $\mathrm{CuO}$-water nanofluid. The skin friction coefficient and the local Nusselt number are more influenced by the nanoparticle volume fraction than the type of nanoparticles. This observation is in agreement with Oztop and Abu-Nada [33]. In addition, water has the lowest skin friction coefficient and the local Nusselt number compared with $\mathrm{CuO}, \mathrm{Al}_{2} \mathrm{O}_{3}, \mathrm{TiO}_{2}$ nanofluids. We observe that the skin friction coefficient decreases with increasing nanoparticle volume fraction, and the same trend is observed in the case of the heat transfer coefficient. Table 5 further shows that for a particular nanoparticle volume fraction, the skin friction coefficient increases with an increase in the unsteadiness parameter. A similar trend is observed in the case of the heat transfer coefficient. 
Table 7 Comparison of $-f^{\prime \prime}(0)$ obtained by bvp4c and SRM for different values of nanoparticle volume fraction with $\mathrm{Al}_{2} \mathrm{O}_{3}$-water nanofluid for fixed values of $\operatorname{Pr}=6.7850, r_{1}=2, m=1.5$ and $\omega=0.75$

\begin{tabular}{|c|c|c|c|c|c|c|}
\hline \multirow[t]{2}{*}{ Quantity } & \multirow[t]{2}{*}{$\phi$} & \multicolumn{2}{|c|}{ Basic SRM } & \multicolumn{2}{|c|}{ SRM with SOR } & \multirow[t]{2}{*}{ bvp4c } \\
\hline & & Iter & $-f^{\prime \prime}(0)$ & Iter & $-f^{\prime \prime}(0)$ & \\
\hline $\begin{array}{l}N_{R}=1 \\
S=1 \\
D=1\end{array}$ & $\begin{array}{l}0.05 \\
0.1 \\
0.15 \\
0.2\end{array}$ & $\begin{array}{l}23 \\
23 \\
23 \\
23\end{array}$ & $\begin{array}{l}1.32762309 \\
1.31890045 \\
1.29654739 \\
1.26231187\end{array}$ & $\begin{array}{l}14 \\
14 \\
13 \\
14\end{array}$ & $\begin{array}{l}1.32762309 \\
1.31890045 \\
1.29654739 \\
1.26231187\end{array}$ & $\begin{array}{l}1.32762309 \\
1.31890045 \\
1.29654739 \\
1.26231187\end{array}$ \\
\hline $\begin{array}{l}N_{R}=5 \\
S=1 \\
D=2\end{array}$ & $\begin{array}{l}0.05 \\
0.1 \\
0.15 \\
0.2\end{array}$ & $\begin{array}{l}23 \\
23 \\
23 \\
23\end{array}$ & $\begin{array}{l}1.32762309 \\
1.31890045 \\
1.29654739 \\
1.26231187\end{array}$ & $\begin{array}{l}14 \\
14 \\
14 \\
13\end{array}$ & $\begin{array}{l}1.32762309 \\
1.31890045 \\
1.29654739 \\
1.26231187\end{array}$ & $\begin{array}{l}1.32762309 \\
1.31890045 \\
1.29654739 \\
1.26231187\end{array}$ \\
\hline $\begin{array}{l}N_{R}=10 \\
S=0.5 \\
D=5\end{array}$ & $\begin{array}{l}0.05 \\
0.1 \\
0.15 \\
0.2 \\
\end{array}$ & $\begin{array}{l}38 \\
38 \\
37 \\
37\end{array}$ & $\begin{array}{l}1.17348812 \\
1.16577817 \\
1.14602026 \\
1.11575944 \\
\end{array}$ & $\begin{array}{l}14 \\
14 \\
14 \\
13\end{array}$ & $\begin{array}{l}1.17348812 \\
1.16577817 \\
1.14602026 \\
1.11575944\end{array}$ & $\begin{array}{l}1.17348812 \\
1.16577817 \\
1.14602026 \\
1.11575944 \\
\end{array}$ \\
\hline
\end{tabular}

Table 8 Comparison of $-g^{\prime}(0)$ obtained by bvp4c and SRM for different values of nanoparticle volume fraction with $\mathrm{Al}_{2} \mathrm{O}_{3}$-water nanofluid for fixed values of $\operatorname{Pr}=6.7850, r_{1}=2, m=1.5$ and $\omega=0.75$

\begin{tabular}{|c|c|c|c|c|c|c|}
\hline \multirow[t]{2}{*}{ Quantity } & \multirow[t]{2}{*}{$\phi$} & \multicolumn{2}{|c|}{ Basic SRM } & \multicolumn{2}{|c|}{ SRM with SOR } & \multirow[t]{2}{*}{ bvp4c } \\
\hline & & Iter & $-g^{\prime}(0)$ & Iter & $-g^{\prime}(0)$ & \\
\hline $\begin{array}{l}N_{R}=1 \\
S=1 \\
D=1\end{array}$ & $\begin{array}{l}0.05 \\
0.1 \\
0.15 \\
0.2\end{array}$ & $\begin{array}{l}23 \\
23 \\
23 \\
23\end{array}$ & $\begin{array}{l}2.07754148 \\
1.98429513 \\
1.89386696 \\
1.80581775\end{array}$ & $\begin{array}{l}14 \\
14 \\
13 \\
14\end{array}$ & $\begin{array}{l}2.07754148 \\
1.98429513 \\
1.89386696 \\
1.80581775\end{array}$ & $\begin{array}{l}2.07754148 \\
1.98429513 \\
1.89386696 \\
1.80581775\end{array}$ \\
\hline $\begin{array}{l}N_{R}=5 \\
S=1 \\
D=1\end{array}$ & $\begin{array}{l}0.05 \\
0.1 \\
0.15 \\
0.2\end{array}$ & $\begin{array}{l}23 \\
23 \\
23 \\
23\end{array}$ & $\begin{array}{l}2.43674192 \\
2.35621359 \\
2.27587972 \\
2.19532143\end{array}$ & $\begin{array}{l}14 \\
14 \\
14 \\
13\end{array}$ & $\begin{array}{l}2.43674192 \\
2.35621359 \\
2.27587972 \\
2.19532143\end{array}$ & $\begin{array}{l}2.43674192 \\
2.35621359 \\
2.27587972 \\
2.19532143\end{array}$ \\
\hline $\begin{array}{l}N_{R}=10 \\
S=1 \\
D=1\end{array}$ & $\begin{array}{l}0.05 \\
0.1 \\
0.15 \\
0.2\end{array}$ & $\begin{array}{l}23 \\
23 \\
23 \\
23\end{array}$ & $\begin{array}{l}2.49509121 \\
2.41787850 \\
2.34049758 \\
2.26250267\end{array}$ & $\begin{array}{l}13 \\
14 \\
13 \\
14\end{array}$ & $\begin{array}{l}2.49509121 \\
2.41787850 \\
2.34049758 \\
2.26250267\end{array}$ & $\begin{array}{l}2.49509121 \\
2.41787850 \\
2.34049758 \\
2.26250267\end{array}$ \\
\hline
\end{tabular}

Tables 7 and 8 show the skin friction and heat transfer coefficients for various values of nanoparticle volume fraction and physical parameters. We note that the physical parameters $N_{R}$ and $D$ have no direct effect on the skin friction coefficient, but that the skin friction decreases with an increase in the unsteadiness parameter. From Table 8 we observe that an increase in the thermal radiation parameter produces significant increases in the heat transfer coefficient. The skin friction and heat transfer rates decrease with an increase in the nanoparticle volume fraction.

The effects of the unsteadiness parameter, various nanoparticles, thermal dispersion and radiation parameters on various fluid dynamic quantities are shown in Figures 1-6.

Figure 1 shows the effect of the unsteadiness parameter on the velocity and temperature profiles, respectively, in the case of a $\mathrm{CuO}$-water nanofluid. It is observed that velocity and temperature in the case of a clear fluid are less than those of a $\mathrm{CuO}$-water nanofluid. Increasing the unsteadiness parameter results in a decrease in the thermal boundary layer thickness. We also observe that the temperature distribution decreases with an increase in the unsteadiness parameter in the case of both a clear fluid and the $\mathrm{CuO}$-water nanofluid. These results are consistent with the findings of, among others, Singh et al. [36]. 


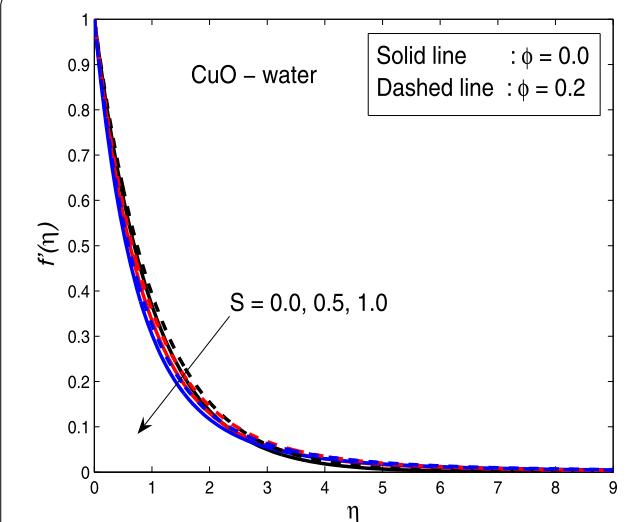

(a)

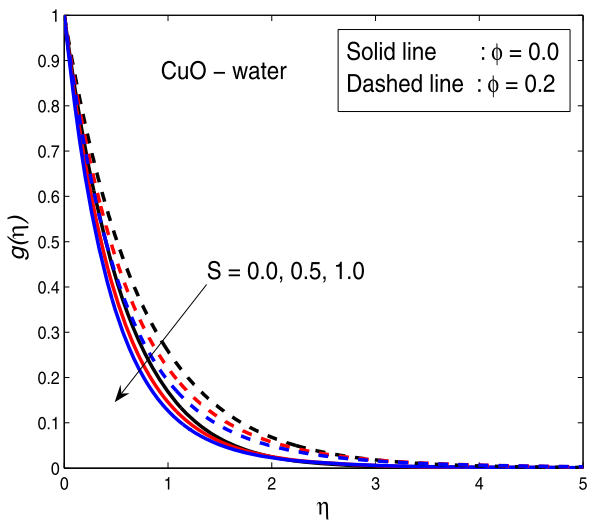

(b)

Figure 1 (a) Velocity and (b) temperature profiles for $\operatorname{Pr}=6.7850, N_{R}=1, D=1, r_{1}=2, m=1.5$.

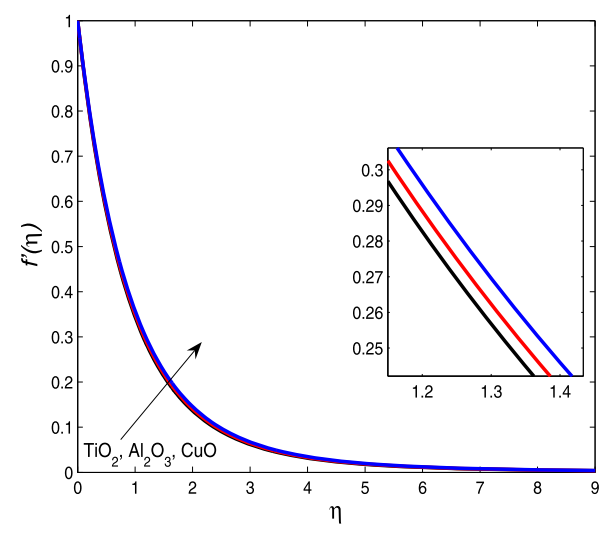

(a)

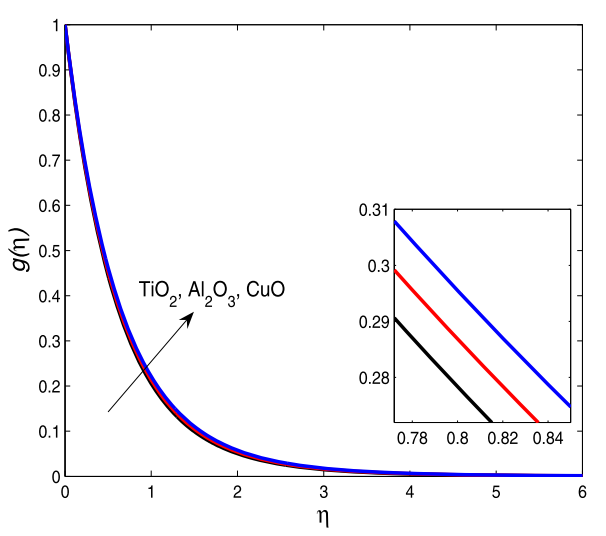

(b)

Figure 2 (a) Velocity and (b) temperature profiles for $\operatorname{Pr}=6.7850, N_{R}=1, D=1, r_{1}=2, m=1.5, S=0.5$, $\phi=0.2$.

Figure 2 shows the velocity and temperature distributions for different nanofluids. It can be observed that the velocity and temperature distributions for different nanoparticles increase gradually far from the surface of the stretching sheet. The fluid velocity and temperatures in the case of a $\mathrm{CuO}$-water nanofluid are less than those in $\mathrm{TiO}_{2}$-water and $\mathrm{Al}_{2} \mathrm{O}_{3}$-water nanofluids.

The effect of thermal dispersion and radiation on the temperature profiles is shown in Figure 3(a). The temperature distribution along the boundary layer increases with increasing thermal dispersion parameter. In Figure 3(b) we observe that the temperature decreases throughout the boundary layer with increasing values of the radiation parameter. At a particular value of $N_{R}$, the temperature increases with the nanoparticle volume fraction. These result can be explained by the fact that a decrease in $N_{R}$ leads to a decrease in the Rosseland radiation absorptivity which in turn increases the rate of radiative heat transferred to the fluid and hence the fluid temperature increases. These results are similar to those reported by El-Aziz [12] in the case of clear fluids. 


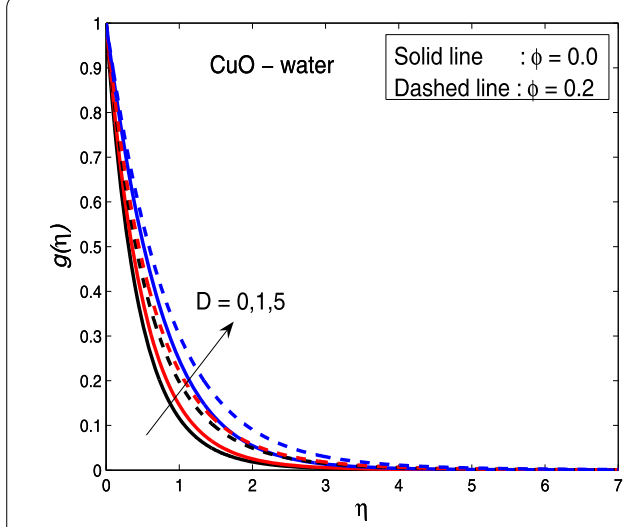

(a)

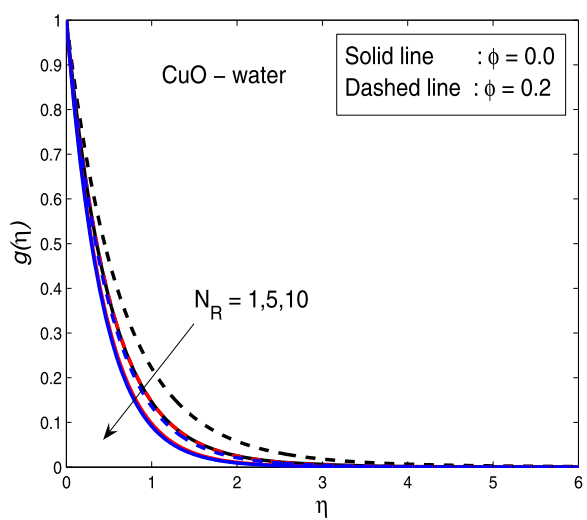

(b)

Figure 3 Temperature profiles for (a) $\operatorname{Pr}=6.7850, S=0.5, N_{R}=1, r_{1}=2, m=1.5$ and (b) $\operatorname{Pr}=6.7850$ $S=0.5, D=1, r_{1}=2, m=1.5$.

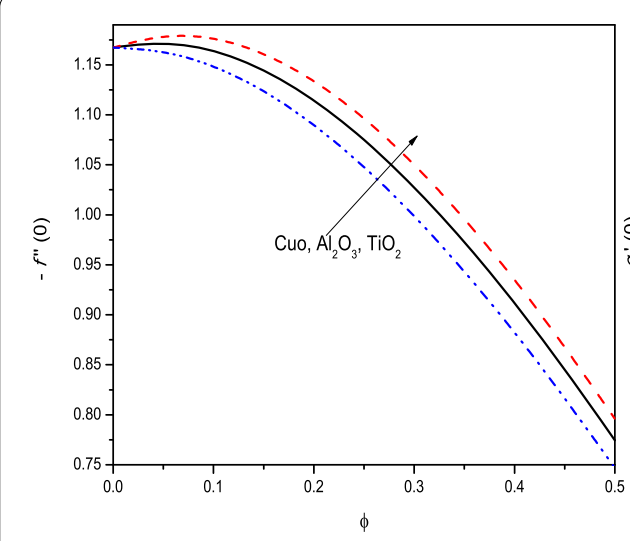

(a)

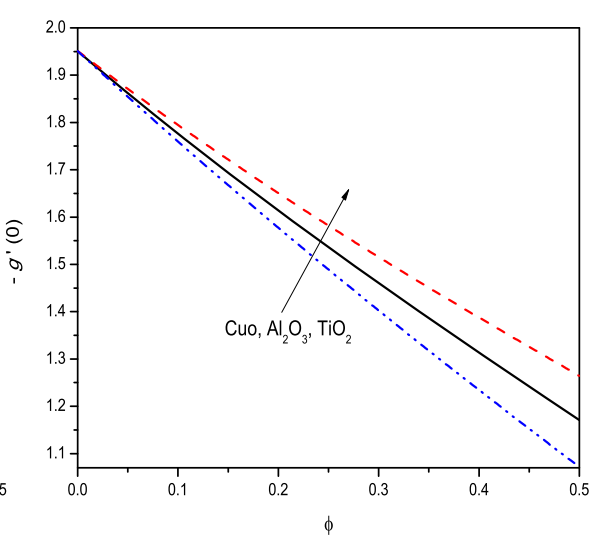

(b)

Figure 4 (a) Skin friction and (b) heat transfer coefficients as a function of nanoparticle volume fraction, when $\operatorname{Pr}=6.7850, S=0.5, D=1, N_{R}=1, r_{1}=2, m=1.5$.

Figure 4 shows the skin friction coefficient as a function of the nanoparticle volume fraction. The skin friction coefficient increases with increasing nanoparticle volume fraction. The maximum value of the skin friction in the case of a $\mathrm{TiO}_{2}$-water nanofluid is attained at higher values of $\phi$ in comparison with $\mathrm{CuO}$-water and $\mathrm{Al}_{2} \mathrm{O}_{3}$ nanofluids. Further, we observe that a $\mathrm{CuO}$-water nanofluid gives a higher drag force in opposition to the flow as compared to the other nanofluids. From Figure 4(b) we observe that the wall heat transfer rates for the nanofluids are increasing functions of $\phi . \mathrm{A} \mathrm{TiO}_{2}$-water nanofluid has higher wall heat transfer rate as compared to the other nanofluids.

The variation of the skin friction and heat transfer rates with the fluid unsteadiness is shown in Figures 5-6 respectively. It is seen that increasing the solid volume fraction leads to decreases of skin friction and to an increase in the rate of heat transfer. An increase in the unsteadiness parameter tends to increase the local Nusselt number. 


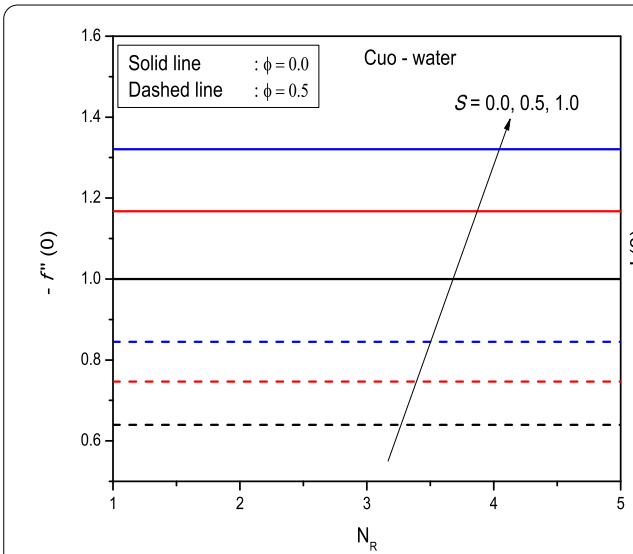

(a)

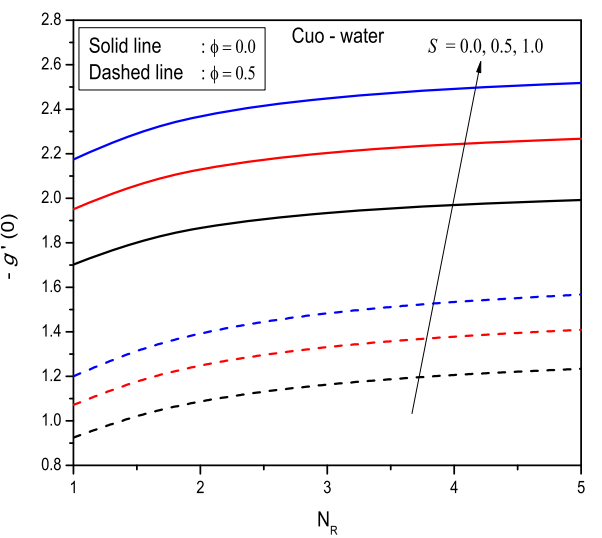

(b)

Figure 5 (a) Skin friction and (b) heat transfer coefficients as a function of $N_{R}$, when $\operatorname{Pr}=6.7850, D=1$, $r_{1}=2, m=1.5$.

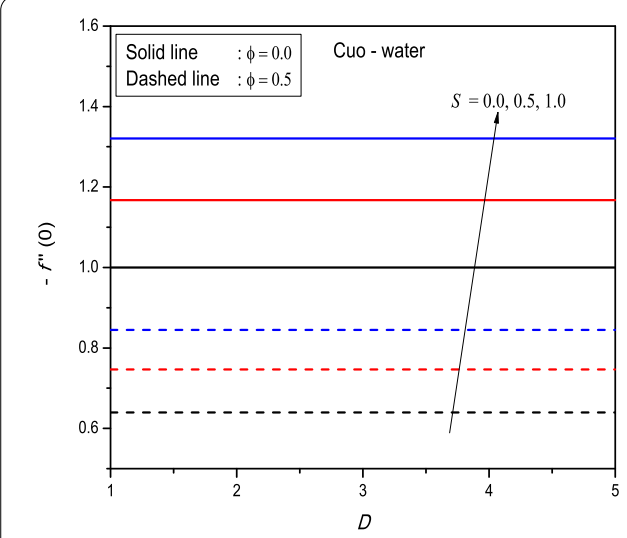

(a)

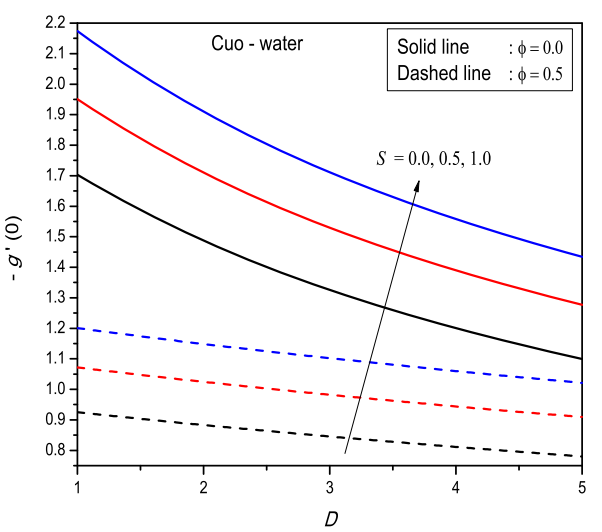

(b)

Figure 6 (a) Skin friction and (b) heat transfer coefficients as a function of $D$, when $\operatorname{Pr}=6.7850, N_{R}=1$, $r_{1}=2, m=1.5$.

\section{Conclusions}

The unsteady boundary layer flow in a nanofluid due to a stretching sheet with thermal dispersion and radiation was studied. The governing equations were transformed into a set of coupled nonlinear differential equations and solved by bvp4c and a novel spectral relaxation method. To determine the convergence, accuracy and general validity of the SRM, the results were compared with the Matlab bvp4c results for selected values of the governing physical parameters. We found that velocity and temperature in the case of a clear fluid are less than those of $\mathrm{CuO}$-water nanofluid. We observe that the temperature decreases throughout the boundary layer with increasing values of the radiation parameter. The convergence rate of the SRM is significantly improved by using the method in conjunction with the SOR method with $\omega<1$. Our findings show that the SRM is accurate and sufficiently robust for use in solving fluid flow problems and as an alternative to the Runge-Kutta and Keller-box schemes in finding solutions of boundary layer equations. 


\section{Competing interests}

The authors declare that they have no competing interests.

\section{Authors' contributions}

The work including proof reading was done by all the authors.

\section{Acknowledgements}

The authors are grateful to the reviewers for their comments and constructive suggestions. We acknowledge financial support from the University of KwaZulu-Natal.

\section{Received: 18 June 2013 Accepted: 24 September 2013 Published: 18 Nov 2013}

\section{References}

1. Crane, LJ: Flow past a stretching plate. Z. Angew. Math. Phys. 21, 645-647 (1970)

2. Gupta, PS, Gupta, AS: Heat and mass transfer on a stretching sheet with suction or blowing. Can. J. Chem. Eng. 55, 744-746 (1977)

3. Sakiadis, BC: Boundary-layer behavior on continuous solid surfaces: I. Boundary-layer equations for two-dimensional and axisymmetric flow. AlChE J. 7, 26-28 (1961)

4. Cortell, R: Effects of viscous dissipation and work done by deformation on the MHD flow and heat transfer of a viscoelastic fluid over a stretching sheet. Phys. Lett. A 357, 298-305 (2006)

5. Hayat, T, Sajid, M: Analytic solution for axisymmetric flow and heat transfer of a second grade fluid past a stretching sheet. Int. J. Heat Mass Transf. 50, 75-84 (2007)

6. Liao, SJ: On the analytic solution of magnetohydrodynamic flows of non-Newtonian fluids over a stretching sheet. J. Fluid Mech. 488, 189-212 (2003)

7. $\mathrm{Xu}, \mathrm{H}$ : An explicit analytic solution for convective heat transfer in an electrically conducting fluid at a stretching surface with uniform free stream. Int. J. Eng. Sci. 43, 859-874 (2005)

8. El-Aziz, MA: Thermal-diffusion and diffusion-thermo effects on combined heat and mass transfer by hydromagnetic three-dimensional free convection over a permeable stretching surface with radiation. Phys. Lett. A 372, 263-272 (2007)

9. El-Aziz, MA: Thermal radiation effects on magnetohydrodynamic mixed convection flow of a micropolar fluid past a continuously moving semi-infinite plate for high temperature differences. Acta Mech. 187, 113-127 (2006)

10. Raptis, A: Flow of a micropolar fluid past a continuously moving plate by the presence of radiation. Int. J. Heat Mass Transf. 41, 2865-2866 (1998)

11. Mahmoud, MAA: Thermal radiation effects on MHD flow of a micropolar fluid over a stretching surface with variable thermal conductivity. Physica A 375, 401-410 (2007)

12. El-Aziz, MA: Radiation effect on the flow and heat transfer over an unsteady stretching sheet. Int. Commun. Heat Mass Transf. 36, 521-524 (2009)

13. Telles, RS, Trevisan, OV: Dispersion in heat and mass transfer natural convection along vertical boundaries in porous media. Int. J. Heat Mass Transf. 36, 1357-1365 (1993)

14. Choi, SUS: Enhancing thermal conductivity of fluids with nanoparticles. In: Proceedings of the ASME International Mechanical Engineering Congress and Exposition, pp. 99-105. ASME FED231/MD66, San Francisco, USA (1995)

15. Masuda, H, Ebata, A, Teramae, K, Hishinuma, N: Alteration of thermal conductivity and viscosity of liquid by dispersing ultra-fine particles. Dispersion of $\mathrm{Al}_{2} \mathrm{O}_{3}, \mathrm{SiO}_{2}$ and $\mathrm{TiO}_{2}$ Ultra-Fine Particles. Netsu Bussei 4, $227-233$ (1993)

16. Das, S, Putra, N, Thiesen, P, Roetzel, W: Temperature dependence of thermal conductivity enhancement for nanofluids. J. Heat Transf. 125, 567-574 (2003)

17. Xuan, Y, Li, Q: Investigation on convective heat transfer and flow features of nanofluids. J. Heat Transf. 125, 151-155 (2003)

18. Trisaksri, V, Wongwises, S: Critical review of heat transfer characteristics of nanofluids. Renew. Sustain. Energy Rev. 11, $512-523(2007)$

19. Wang, XQ, Mujumdar, AS: Heat transfer characteristics of nanofluids: a review. Int. J. Therm. Sci. 46, 1-19 (2007)

20. Kang, HU, Kim, SH, Oh, JM: Estimation of thermal conductivity of nanofluid using experimental effective particle volume. Exp. Heat Transf. 19, 181-191 (2006)

21. Velagapudi, V, Konijeti, RK, Aduru, CSK: Empirical correlations to predict thermophysical and heat transfer characteristics of nanofluids. Therm. Sci. 12, 27-37 (2008)

22. Rudyak, VY, Belkin, AA, Tomilina, EA: On the thermal conductivity of nanofluids. Tech. Phys. Lett. 36, 660-662 (2010)

23. Hady, FM, Ibrahim, FS, Abdel-Gaied, SM, Eid, MR: Radiation effect on viscous flow of a nanofluid and heat transfer over a nonlinearly stretching sheet. Nanoscale Res. Lett. 7, 229 (2012)

24. Olanrewaju, PO, Olanrewaju, MA, Adesanya, AO: Boundary layer flow of nanofluids over a moving surface in a flowing fluid in the presence of radiation. Int. J. Appl. Sci. Tech. 2, 274-285 (2012

25. Mahdy, A: Unsteady mixed convection boundary layer flow and heat transfer of nanofluids due to stretching sheet. Nucl. Eng. Des. 249, 248-255 (2012)

26. Narayana, M, Sibanda, P: Laminar flow of a nanoliquid film over an unsteady stretching sheet. Int. J. Heat Mass Transf. 55, 7552-7560 (2012)

27. Kameswaran, PK, Narayana, M, Sibanda, P, Murthy, PVSN: Hydromagnetic nanofluid flow due to a stretching or shrinking sheet with viscous dissipation and chemical reaction effects. Int. J. Heat Mass Transf. 55, 7587-7595 (2012)

28. Motsa, SS, Makukula, ZG: On spectral relaxation method approach for steady von Karman flow of a Reiner-Rivlin fluid with Joule heating, viscous dissipation and suction/injection. Cent. Eur. J. Phys. 11, 363-374 (2013)

29. Motsa, SS: A new spectral relaxation method for similarity variable nonlinear boundary layer flow systems. Chem. Eng. Commun. (2013). doi:10.1080/00986445.2013.766882

30. Tiwari, RK, Das, MK: Heat transfer augmentation in a two sided lid driven differentially heated square cavity utilizing nanofluids. Int. J. Heat Mass Transf. 50, 2002-2018 (2007)

31. Maxwell-Garnett, JC: Colours in metal glasses and in metallic films. Philos. Trans. R. Soc. Lond. A 203, 385-420 (1904) 
32. Guerin, CA, Mallet, P, Sentenac, A: Effective-medium theory for finite-size aggregates. J. Opt. Soc. Am. A 23, 349-358 (2006)

33. Oztop, HF, Abu-Nada, E: Numerical study of natural convection in partially heated rectangular enclosures filled with nanofluids. Int. J. Heat Fluid Flow 29, 1326-1336 (2008)

34. Canuto, C, Hussaini, MV, Quarteroni, A, Zang, TA: Spectral Methods in Fluid Dynamics. Springer, Berlin (1988)

35. Trefethen, LN: Spectral Methods in MATLAB. SIAM, Philadelphia (2000)

36. Singh, $P$, Jangid, A, Tomer, NS, Sinha, D: Effects of thermal radiation and magnetic field on unsteady stretching permeable sheet in presence of free stream velocity. Int. J. Inf. Math. Sci. 6, 160-166 (2010)

10.1186/1687-2770-2013-242

Cite this article as: Kameswaran et al.: A spectral relaxation method for thermal dispersion and radiation effects in a nanofluid flow. Boundary Value Problems 2013, 2013:242

Submit your manuscript to a SpringerOpen ${ }^{\circ}$ journal and benefit from:

- Convenient online submission

- Rigorous peer review

- Immediate publication on acceptance

- Open access: articles freely available online

- High visibility within the field

- Retaining the copyright to your article

Submit your next manuscript at $>$ springeropen.com 